\title{
Diabetic Foot Ulcer Risk with Diabetic Kidney Disease and Renal Failure among 10,680 Patients
}

\author{
Kamran Mahmood Ahmed Aziz ${ }^{1 *}$ \\ ${ }^{I}$ Consultant Diabetes, Endocrinology, Metabolism; Research Scientist and Clinical Investigator, Aseer Endocrine \& Diabetes Center of \\ Aseer Central Hospital, Ministry of Health, Abha, Saudi Arabia.
}

Received 29 May 2021; Revised 06 October 2021; Accepted 17 October 2021; Published 01 December 2021

\begin{abstract}
Objectives: Patients with Diabetic Kidney Disease (DKD) and foot ulcer have poor prognosis. However, no study have found association of diabetic foot ulcer (DFU) with diabetic kidney dysfunction and their co-existing risk factors. Materials and Methods: This cross sectional study collected the data for 10,680 patients for 15 years. All variables were analyzed biochemically and statistically by standardized methodology. Results: Levels of $\mathrm{HbA1c}$, creatinine, systolic and diastolic blood pressures, microalbuminuria, spot urine protein, and spot urine protein to creatinine ratio were higher among the groups with foot ulcers (p-value $<0.0001$ for all). Average ABI was observed to be lower among the groups demonstrating nephropathy and DKD ( $\mathrm{p}=0.025$ and 0.022 respectively. DFU was significantly associated with HTN (odds ratio $2.2 ; 95 \%$ CI 1.66 to $2.9 ; \mathrm{p}<0.0001$ ), nephropathy (odds ratio $4.77 ; 95 \%$ CI 3.53 to $6.5 ; \mathrm{p}<0.0001$ ) and DKD (odds ratio 4.77 and 6.83 ; $95 \%$ CI 4.6 to 10.2 ; p < 0.0001 ). HbA1c of $7.8 \%$ was $60 \%$ sensitive and $52 \%$ specific for the development of DFU. Creatinine of $1.2 \mathrm{mg} / \mathrm{dl}$ was $75 \%$ sensitive and $48 \%$ specific for DFU. Spot urine protein excretion from nephrons of $35 \mathrm{mg} / \mathrm{dl}$ was $88 \%$ sensitive and $90 \%$ specific for the development of DFU. Conclusion: Nephropathy/DKD are risk factors for the development of DFU. With optimal diabetes control, regular and routine assessment of the feet and early screening of diabetic patients for neuropathy, nephropathy, hypertension, dyslipidaemia and other diabetic complications are essential.
\end{abstract}

Keywords: Diabetic Foot Ulceration; Diabetic Kidney Disease; Serum Creatinine; Microalbumin; Proteinuria; Renal Failure.

\section{Introduction}

Diabetes mellitus is a global health problem. Diabetic foot ulcer (DFU) or diabetic foot infection (DFI) are the major cause of lower extremity amputations (LEA). More than $25 \%$ of diabetic patients suffer from foot amputations during their lifetime and more than $85 \%$ of lower extremity amputation are due to foot infections or ulcerations. Furthermore, diabetes is now the most common cause of preventable Charcot neuroarthropathy. Diabetic foot problems are considered a complex group of pathologies and also known as "diabetic foot syndrome" (DFS), including both neuropathy and vasculopahty or vascular insufficiency [1-3]. Periodic neurological assessment and examination is essential with measurement of ankle brachial index (ABI) and for foot pulses.

Diabetes is major cause of other microvascular diseases, and leading to microvascular complications such as retinopathy, nephropathy, and chronic renal failure or end stage renal disease (ESRD). Landmark diabetes control and complication trial (DCCT) and UK Prospective Diabetes Study (UKPDS) have shown that reductions in HbA1c levels will reduce the risk of diabetic macrovascular and microvascular complications [4].

* Corresponding author: drkamran9999@yahoo.com

dol http://dx.doi.org/10.28991/SciMedJ-2021-0304-6

$>$ This is an open access article under the CC-BY license (https://creativecommons.org/licenses/by/4.0/).

(C) Authors retain all copyrights. 
Diabetes mellitus is a strong risk factor for chronic kidney disease (CKD). Chronic involvement of the kidney in diabetic state is currently termed as diabetic kidney disease (DKD). Initially, under the influence of high blood pressure (HTN), diabetic kidney disease results in microalbuminuria or gross proteinuria, nephropathy and may to end stage renal disease (ESRD) if diabetes is uncontrolled. Furthermore, hypertension (HTN) or elevated systolic and diastolic pressures are also major risk factors for the nephropathy, proteinuria and ESRD. HTN and Atherosclerotic cardiovascular disease (ASCVD) are also leading cause of morbidity and mortality among diabetics, coexisting with DKD $[5,6]$.

Moreover, research trials have demonstrated that a low ankle brachial index $(\mathrm{ABI})$ of $\leq 0.9$ is a predictor and risk for the coronary artery disease (CAD) and peripheral vascular disease (PVD). Research has demonstrated that chronic renal dysfunction is also associated with low ABI and with high mortality among patients on hemodialysis [7-10].

Microalbuminuria (30-300 mg/L albumin excretion in urine) is considered a risk biomarker for the cardiovascular disease. However, it does not represent actual underlying renal injury [11-13]. Recently, spot urine protein UPr and its ratio with spot urine creatinine UCr is also recommended for diagnosing and monitoring proteinuria; this inexpensive, easily and quickly performed at tertiary care endocrine, diabetes and hospital settings. Spot urine protein estimation is very helpful when microalbumin exceeds $300 \mathrm{mg}$ albumin per day (gross proteinuria). The spot urine protein/creatinine ratio (UPr/UCr or PCR) correlates well with total protein excretion per day, and provides good estimation of protein excretion from the kidney [14-17].

There are some research trials which have demonstrated association between diabetic foot ulceration and development of kidney dysfunction or failure. In the past decade, much work was done to find association between these two pathologies to prevent health cost burden [18]. However, much less work has been published on the risk of developing renal failure (CKD/DKD), associated co-morbidities, risk factors and proteinuria with DFU. There is a need to study associations between these risk factors, and development of DKD with DFU. Hence according to the literature review, we hypothesized that the risk of developing DFU with nephropathy and DKD was associated with other co-morbidities also, including HTN or increased systolic/diastolic blood pressures, increased levels of serum creatinine, microalbumin, and spot urine protein, which was not studied previously in such a detailed manner. For the assessment of glycemic control, HbA1c was also tested. Levels of these variables were measured with or without DFU and associations with HTN, nephropathy and DKD.

\section{Study Design and Methods}

This is a prospective cross sectional cohort study, conducted at the diabetology clinic of Aseer Endocrine and Diabetes Center of Aseer Central Hospital, Ministry of Health, Saudi Arabia. Study started in August 2005, until September 2020 for more than fifteen years. 10,680 diabetic patients were selected for the study. We included both type- 1 and type- 2 diabetic patients. Children of less than 13 years of age, patients with severe liver disease, urinary tract infection, known cases of nephrotic syndrome before the onset of diabetes, with end stage renal disease (ESRD) or dialysis and pregnant subjects were excluded from this study. Blood pressure (BP) was measured by standardized methodology. BP of $\geq 140 / 90$ was labelled as hypertension (HTN). Patients with active foot ulcer (of any grade or severity) and regular follow up in diabetic foot clinic were labeled as DFU or DIF.

FDA approved arterial Doppler ultrasonic device (atys Mèdical Doppler System Inc. USA) was used to measure ABI. Measurements were carried in resting and supine position. Brachial pressure in right arm was measured by doppler probe $(8 \mathrm{MHz})$. This was then applied to right foot arteries (dorsalis pedis or posterior tibial artery). Artery with higher pressure was recorded. Right ABI was calculated as ABI = brachial pressure / foot pressure. Same clinical method was applied to measure left ABI. Average ABI for both feet was calculated for statistical analysis with nephropathy and DKD.

\subsection{Laboratory Methods}

Blood samples for clinical chemistry was collected in fasting state. Serum creatinine (mg/dl) was quantitatively measured by CREA methodology by Dimension ${ }^{\circledR}$ clinical chemistry device (Siemens Healthcare Diagnostics Inc. Newark, DE 19714, USA). This technique involves picrate for the measurement of creatinine in plasma and urine. In the presence of a strong base $\mathrm{NaOH}$, picrate chemically reacts with creatinine to form a red chromophore. The rate of increasing absorbance at $510 \mathrm{~nm}$ due to the formation of this chromophore is directly proportional to the creatinine concentration in the sample of blood or urine and which, is measured using by a bichromatic $(510,600 \mathrm{~nm})$ rate methodology. Patients with serum creatinine $\geq 1.5 \mathrm{mg} / \mathrm{dl}$ were considered as CKD or DKD

HbA1c was measured by A1c Flex® Reagent by the Dimension ${ }^{\circledR}$ clinical chemistry system (Siemens healthcare diagnostics Inc. Newark, DE 19714, USA). This detects in vitro quantitatively both percent hemoglobin A1c and total haemoglobin. The techniques is based on a turbidimetric inhibition immunoassay (TINIA) principle, and the measurement of total haemoglobin is based on a modification of the alkaline hematin reaction, an NGSP certified 
methodology. \% HbA1c in percent was calculated by the percentage of total haemoglobin that is glycated (in g/dL), which was then standardized according to the DCCT results.

Nephropathy detection was carried out by the measurement of albumin or protein in urine. QuikCheck ${ }^{\mathrm{TM}}$ urinalysis reagent strips (ACON biotech, Co., Ltd.) was used to detect gross proteinuria (macroalbuminuria). Simply, this technique involves the phenomenon of $\mathrm{pH}$ indicators, releasing hydrogen ions to the protein. Samples demonstrating gross proteinuria (macroalbuminuria) by the colour change of the reagent strips (from $1+$ to $4+$ proteins) were considered "nephropathy". Microalbumin was detected in urine by MALB method (Dimension ${ }^{\circledR}$ clinical chemistry system device, Siemens Healthcare Diagnostics Inc. Newark, DE 19714, USA). This measures albumin in vitro quantitatively $(\mathrm{mg} / \mathrm{L})$ by particle-enhanced turbidimetric inhibition immunoassay (PETINIA) methodology by colour change. Samples positive for microalbuminuria were labelled as nephropathy.

Spot urine protein UCFP (Urinary/ Cerebrospinal Fluid Protein) was measured by Dimension $®$ clinical chemistry system (Siemens healthcare diagnostics Inc. Newark, DE 19714, U.S.A). This detects in vitro total protein in human urine and cerebrospinal fluid directly and quantitatively by pyrogallol red molybdenum method (Y. Fujita, I. Mori and S. Kitano methodology). In the chemical reaction, pyrogallol red combined with sodium molybdate to form a red complex with maximum absorbance at $470 \mathrm{~nm}$. The protein in the sample reacted with this complex in acid solution to form a bluish-purple coloured complex, which absorbs at $600 \mathrm{~nm}$. The absorbance at $600 \mathrm{~nm}$ is directly proportional to the concentration of protein in the sample. The analyte concentration is determined by calculation of a logit curve fit on a previously stored calibration curve. PCR (protein to creatinine ratio) was measured by the formula, PCR = spot urine protein / spot urine creatinine. All laboratory samples were retrieved by Natcom Hospital Information System (NATCOM HIS; National Computer System Co. Ltd.

\subsection{Statistical Methods}

Clinical data was analyzed by IBM® SPSS ${ }^{\circledR}$ statistics, version 20 (IBM Corp.). Data was summarized as percentages with mean \pm SD and $95 \%$ CI. Independent t-test was used to test the significance between the groups of variables. Pearson chi-square $\left(\chi^{2}\right)$ was used to find significant associations among DFU with HTN, nephropathy and DKD. Logistic Regression, Odds Ratio were considered to measure associations of DFU with HTN, nephropathy, and DKD/CKD. ROC was used to find cutoff values, sensitivity and specificity for HbA1c, creatinine and spot urine protein. Statistical power of $90 \%$ and p-values (two-sided) of less than 0.05 were considered significant.

The study was reviewed and approved in 2005 by the research committee of Aseer Diabetes and Endocrine Center, and all methodologies on subjects reported in were in accordance with the Helsinki Declaration of 1975 (revised in 2008).

\section{Results}

Table 1 presents demographic data. There were 6190 (58\%) males and 4490 (42\%). 1545 (14.5\%) were type-1 and $9135(85.5 \%)$ subjects were type- $2.12 \%$ of patients demonstrated diabetic foot infection. Nephropathy was observed in $39 \%$ of patients; $43 \%$ was hypertensive and $15 \%$ demonstrated DKD/CKD.

Table 1. Demographic data of diabetic patients

\begin{tabular}{lll}
\hline Variables & \multicolumn{2}{l}{$\mathrm{N}(\%) ;$ Totals = 10680 } \\
\hline \multirow{2}{*}{ Gender } & Male & Female \\
\cline { 2 - 3 } & $6190(58 \%)$ & $4490(42 \%)$ \\
\hline \multirow{2}{*}{ Type of Diabetes } & Type-1 & Type-2 \\
\cline { 2 - 3 } Hypertension & $1545(14.5 \%)$ & $9135(85.5 \%)$ \\
\hline \multirow{2}{*}{ Nephropathy } & Positive & Negative \\
\cline { 2 - 3 } & $4592(43 \%)$ & $6088(57 \%)$ \\
\hline \multirow{2}{*}{$\begin{array}{l}\text { Diabetic Kidney Disease } \\
\text { (DKD/ CKD) status }\end{array}$} & Positive & Negative \\
\cline { 2 - 3 } & $4166(39 \%)$ & $6514(61 \%)$ \\
\hline \multirow{2}{*}{ Diabetic foot infection } & $1602(15 \%)$ & Negative \\
\cline { 2 - 3 } & Positive & $9078(85 \%)$ \\
\cline { 2 - 3 } & $1281(12 \%)$ & Negative \\
\hline
\end{tabular}

Descriptive statistics for variables are shown in Table 2. Mean age was 54 years while mean duration of diabetes was observed to be 16 years for the subjects studied. 
Table 2. Variables with mean \pm SD

\begin{tabular}{lc}
\hline Variables & Mean \pm SD \\
\hline Age (years) & $54 \pm 13.7$ \\
Diabetes duration (years) & $16 \pm 8.7$ \\
Serum creatinine (mg/dl) & $0.965 \pm 0.679$ \\
HbA1c \% (g/dl) & $7.8 \pm 1.5$ \\
Systolic BP (mmHg) & $129 \pm 15.8$ \\
Diastolic BP (mmHg) & $79.6 \pm 9.3$ \\
Microalbumin in urine (mg/L) & $74.6 \pm 106.7$ \\
Spot Urine protein (mg/dl) & $53.6 \pm 29.5$ \\
Spot Urine creatinine (mg/dl) & $121 \pm 73.7$ \\
Protein to creatinine ratio (PCR) & $0.61 \pm 2.03$ \\
Average ABI (right and left side of body) & $1.23 \pm 0.33$ \\
\hline
\end{tabular}

Significant t-test among group of variables (HbA1c, systolic and diastolic blood pressures, microalbuminuria, spot urine protein, creatinine, and their ratio) is presented in Table 3. Levels of these variables were high among the groups demonstrating diabetic foot infection, with significant $\mathrm{p}$-values $(\mathrm{p}<0.05)$ as can be observed in the table.

Table 3. T-test between groups of variables (with and without foot ulcer) with mean \pm SD and p-values

\begin{tabular}{|c|c|c|c|c|c|}
\hline \multirow{2}{*}{ Variables and indicators } & \multicolumn{5}{|c|}{ Comparison of variables with or without Foot Ulcer } \\
\hline & \multicolumn{2}{|c|}{ Mean $\pm 95 \%$ CI } & F-value & T-value & P-values \\
\hline \multirow{3}{*}{ HbA1c \% (g/dl) } & With Foot Ulcer & Without Foot Ulcer & \multirow{3}{*}{2.1} & \multirow{3}{*}{3.1} & \multirow{3}{*}{0.002} \\
\hline & $8.6 \pm 1.61$ & $7.8 \pm 1.47$ & & & \\
\hline & 8 to 8.7 & 7.7 to 7.9 & & & \\
\hline \multirow{3}{*}{ Creatinine $(\mathrm{mg} / \mathrm{L})$} & With Foot Ulcer & Without Foot Ulcer & \multirow{3}{*}{83} & \multirow{3}{*}{8.85} & \multirow{3}{*}{$<0.0001$} \\
\hline & $1.3 \pm 1.02$ & $0.898 \pm 0.585$ & & & \\
\hline & 1.17 to 1.44 & 0.87 to 0.93 & & & \\
\hline \multirow{3}{*}{ Systolic BP (mmHg) } & With Foot Ulcer & Without Foot Ulcer & \multirow{3}{*}{5.5} & \multirow{3}{*}{8.3} & \multirow{3}{*}{$<0.0001$} \\
\hline & $136.5 \pm 18$ & $127 \pm 15$ & & & \\
\hline & 135 to 139 & 126 to 128 & & & \\
\hline \multirow{3}{*}{ Diastolic BP (mmHg) } & With Foot Ulcer & Without Foot Ulcer & \multirow{3}{*}{5.8} & \multirow{3}{*}{5.97} & \multirow{3}{*}{$<0.0001$} \\
\hline & $83 \pm 10$ & $78 \pm 8$ & & & \\
\hline & 82 to 95 & 78 to 80 & & & \\
\hline \multirow{3}{*}{ Microalbumin in urine $(\mathrm{mg} / \mathrm{L})$} & With Foot Ulcer & Without Foot Ulcer & \multirow{3}{*}{99.5} & \multirow{3}{*}{10.5} & \multirow{3}{*}{$<0.0001$} \\
\hline & $170.3 \pm 198$ & $55.2 \pm 78$ & & & \\
\hline & 131.2 to 297 & 49.2 to 81.3 & & & \\
\hline \multirow{3}{*}{ Spot Urine protein $(\mathrm{mg} / \mathrm{dl})$} & With Foot Ulcer & Without Foot Ulcer & \multirow{3}{*}{202} & \multirow{3}{*}{13.6} & \multirow{3}{*}{$<0.0001$} \\
\hline & $270 \pm 176$ & $39.8 \pm 29$ & & & \\
\hline & 135.6 to 440 & 17.3 to 65 & & & \\
\hline \multirow{3}{*}{ Spot Urine creatinine $\mathrm{mg} / \mathrm{dl}$} & With Foot Ulcer & Without Foot Ulcer & \multirow{3}{*}{0.335} & \multirow{3}{*}{0.189} & \multirow{3}{*}{0.850} \\
\hline & $119 \pm 66$ & $120.5 \pm 90$ & & & \\
\hline & 114.5 to 124.3 & 108 to 133 & & & \\
\hline \multirow{3}{*}{$\begin{array}{l}\text { Urine Protein to Creatinine Ratio } \\
\text { (PCR) }\end{array}$} & With Foot Ulcer & Without Foot Ulcer & \multirow{3}{*}{166.8} & & \\
\hline & $1.93 \pm 3.7$ & $0.23 \pm 0.95$ & & 11 & $<0.0001$ \\
\hline & 1.4 to 2.43 & 0.16 to 0.3 & & & \\
\hline
\end{tabular}

Table 4 demonstrates average ABI values with nephropathy and DKD. Average ABI values were lower among the groups with nephropathy and DKD ( $1.2 \pm 0.28$ vs. $1.29 \pm 0.38$ and $1.15 \pm 0.23$ vs. $1.25 \pm 0.33$, respectively). 
Table 4. Significant associations between ABI and groups of variables (nephropathy and DKD) with mean \pm SD and p-values

\begin{tabular}{|c|c|c|c|c|c|}
\hline \multirow{3}{*}{ Variables and indicators } & \multicolumn{5}{|c|}{ Comparison of variables with or without nephropathy and DKD } \\
\hline & \multicolumn{2}{|c|}{ Mean $\pm 95 \%$ CI } & F-value & T-value & P-values \\
\hline & With Nephropathy & Without Nephropathy & \multirow[b]{2}{*}{5} & \multirow[b]{2}{*}{1.99} & \multirow[b]{2}{*}{0.025} \\
\hline ABI (average) & $\begin{array}{l}1.2 \pm 0.28 \\
1.16 \text { to } 1.24\end{array}$ & $\begin{array}{l}1.29 \pm 0.38 \\
1.22 \text { to } 1.34\end{array}$ & & & \\
\hline \multirow[b]{2}{*}{ ABI (average) } & With DKD & Without DKD & \multirow[b]{2}{*}{2} & \multirow[b]{2}{*}{1.7} & \multirow[b]{2}{*}{0.022} \\
\hline & $\begin{array}{l}1.15 \pm 0.23 \\
1 \text { to } 1.2\end{array}$ & $\begin{array}{l}1.25 \pm 0.33 \\
1.2 \text { to } 1.3\end{array}$ & & & \\
\hline
\end{tabular}

Pearson's $\left(\chi^{2}\right)$ and logistic regression with odds ratio is presented in table-5. DFU was significantly associated with HTN (odds ratio 2.2; $95 \%$ CI 1.66 to $2.9 ; \mathrm{p}<0.0001$ ). Similarly, DFU was significantly associated with the development of nephropathy and DKD/CKD; odds ratio 4.77 (95\% CI 3.53 to $6.5 ; \mathrm{p}<0.0001)$ and 6.83 (95\% CI 4.6 to $10.2 ; \mathrm{p}<0.0001)$, respectively.

Table 5. Significant Pearson's $\left(\chi^{2}\right)$ results for the variables HTN, nephropathy, and CKD/DKD

\begin{tabular}{|c|c|c|c|c|}
\hline Variables & $\begin{array}{l}\text { Pearson's }\left(\chi^{2}\right) ; \\
\text { p-value }\end{array}$ & $\begin{array}{c}\text { Fisher's exact test } \\
\text { p-value }\end{array}$ & $\begin{array}{l}\text { Linear-by-linear } \\
\text { Association p-value }\end{array}$ & $\begin{array}{l}\text { Logistic Regression and } \\
\text { Odds Ratio (95\% CI) }\end{array}$ \\
\hline Diabetic foot ulcer and HTN & $<0.0001$ & $<0.0001$ & $<0.0001$ & $2.2(1.66$ to 2.9$)$ \\
\hline Diabetic foot ulcer and nephropathy & $<0.0001$ & $<0.0001$ & $<0.0001$ & $4.77(3.53$ to 6.5$)$ \\
\hline Diabetic foot ulcer and DKD/CKD & $<0.0001$ & $<0.0001$ & $<0.0001$ & 6.83 (4.6 to 10.2$)$ \\
\hline
\end{tabular}

Table 6 demonstrates ROC results, AUC and p-values for DFU with HbA1c, creatinine and spot urine protein. HbA1c of $7.8 \%$ was $60 \%$ sensitive and $52 \%$ specific for the development of DFU (AUC $=0.58 ; 95 \%$ CI 0.521 to $0.624 ; \mathrm{p}<0.0006$ ). Creatinine of $1.2 \mathrm{mg} / \mathrm{dl}$ was $75 \%$ sensitive and $48 \%$ specific for DFU (AUC $=0.58 ; 95 \%$ CI 0.640 to $0.715 ; \mathrm{p}<0.0001$ ). Spot urine protein excretion from nephrons of $35 \mathrm{mg} / \mathrm{dl}$ was $88 \%$ sensitive and $90 \%$ specific for the development of DFU (AUC $=0.585 ; 95 \%$ CI 0.555 to $0.616 ; p<0.0001$ ). Sensitivity and specificity for the development of foot ulcer with these variables are graphically represented by ROC in Figures 1 to 3, respectively.

Table 6. Results of ROC with AUC, $95 \%$ CI, p-values and coordinate cut-off points

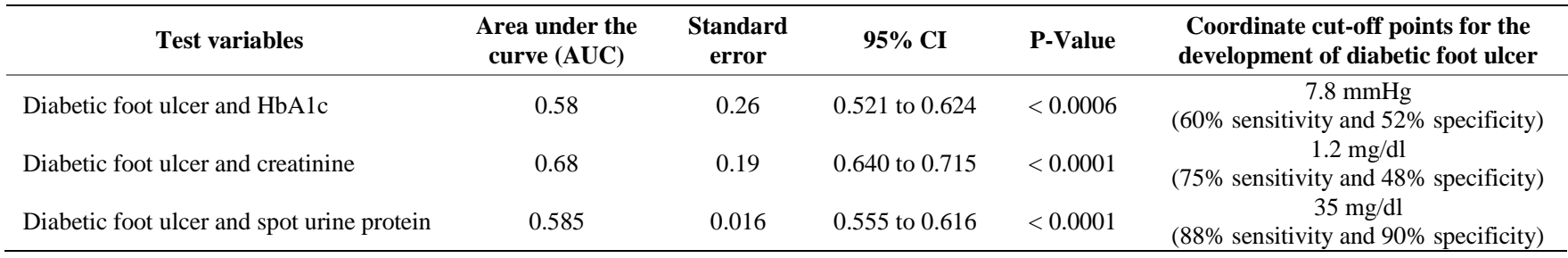

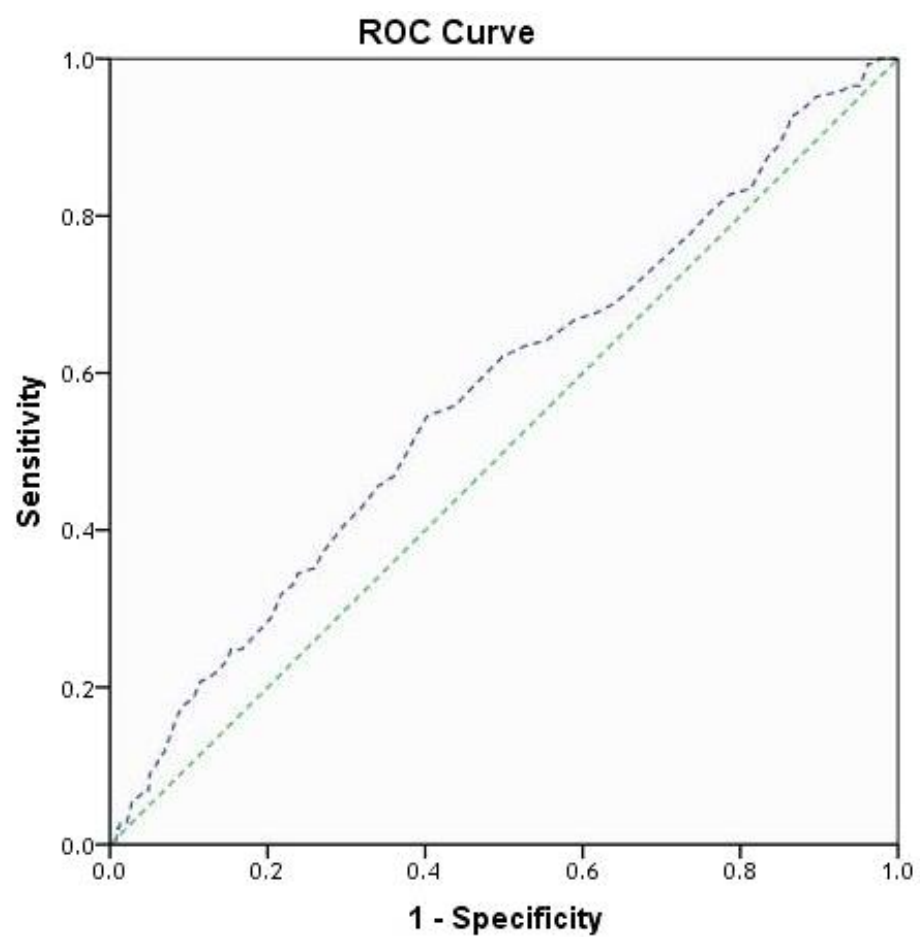

Figure 1. ROC for diabetic foot ulcer and HbA1c 


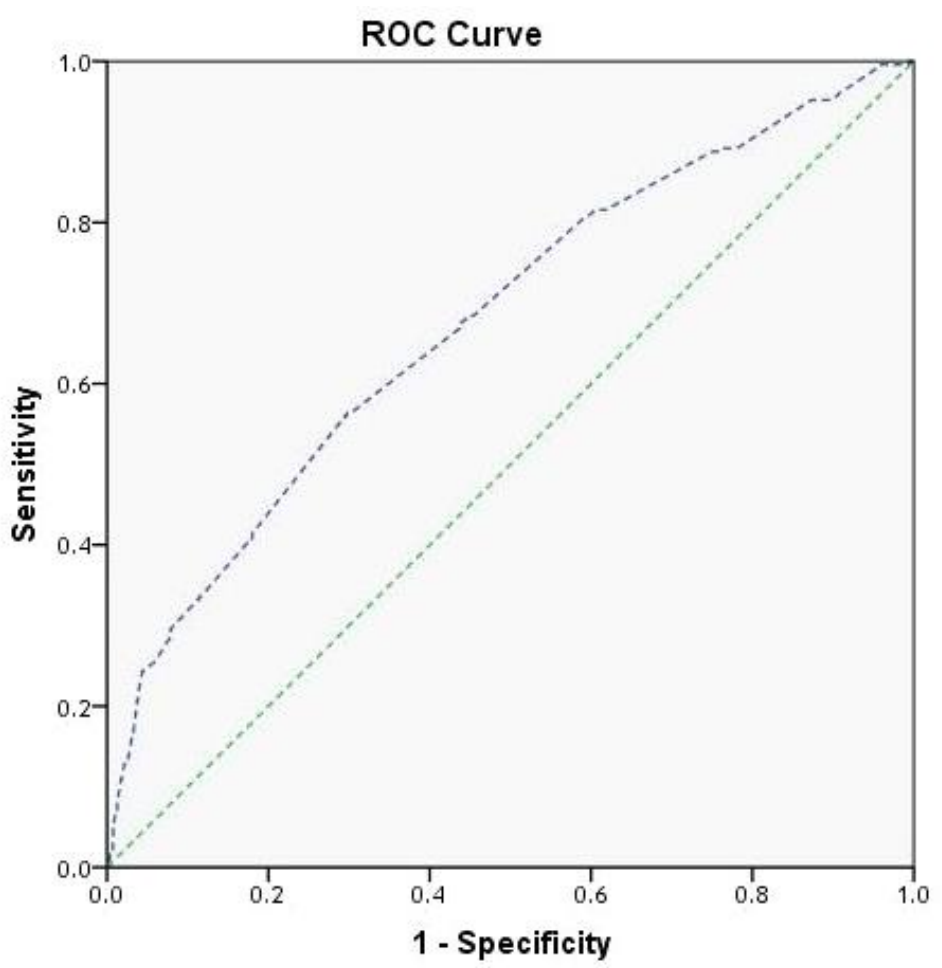

Figure 2. ROC for diabetic foot ulcer and serum creatinine

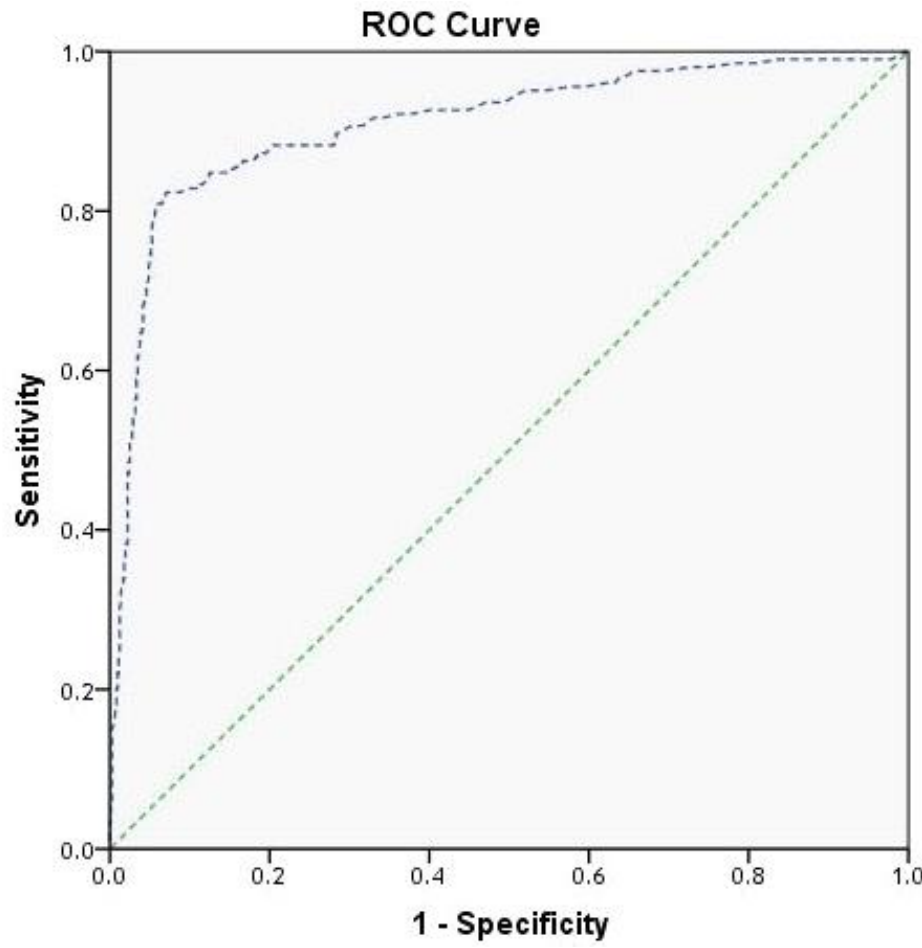

Figure 3. ROC for diabetic foot ulcer and spot urine protein

\section{Discussion}

Diabetic renal failure and nephropathy has been demonstrated to be associated with diabetic septic foot ulceration and amputation $[19,20]$. Additionally, diabetic patient on dialysis are also at risk of development of foot ulceration $[21,22]$. Moreover, uraemia and renal failure have been associated and are the risk factors for non-healing neuroischaemic foot ulcers and amputations. Uraemia has a direct negative effect on ulcer healing as compared to nonuraemic patients [23]. Hence, in other words, DKD/CKD has strong association and is a risk for the development of DFU, chronic non-healing ulcers and amputations, vice versa. It is well known that diabetes effects the kidney gradually and chronically for several years and leads to decrease in the kidney function or glomerular filtration rate (GFR); and if untreated at earlier stages, may lead to ESRD [24]. Hence, our study investigated association of DFU 
with renal failure or DKD/CKD. Out of 10,680 patients, $12 \%$ presented with DFU. $43 \%$ was hypertensive. $39 \%$ demonstrated nephropathy, while $15 \%$ was diagnosed as DKD/CKD.

According to Table 3, it was observed that levels of HbA1c, serum creatinine, systolic and diastolic BP, microalbumin in urine, spot urine protein and PCR were higher among the patients with DFU, with significant pvalues. This statistical analysis suggests that elevated HbA1c or poor glycemic control contribute to the development of DFU and impairs wound healing. Furthermore, elevated BP significantly effects renal physiology with excretion of increased levels of microalbumin and proteins into the urine and development of nephropathy. All these pathophysiologic conditions and DFU are inter-related. Hence, patients with DFU has demonstrated elevated serum creatinine and renal impairment (DKD/CKD). Additionally, as demonstrated by table-4, ABI values were lower among the patients demonstrating nephropathy and DKD/CKD (serum creatinine $>1.5 \mathrm{mg} / \mathrm{dl}$ ), with significant pvalues; this suggests that renal involvement in diabetic metabolic state is significantly associated with lower blood supply to the feet, indicating strong relationship between atherosclerotic risk and impaired renal function in diabetic state. This brings attention of clinical researchers to investigate this cause effect relationship at multi-center level. Moreover, this data was further supported by conducting $\chi^{2}$ analysis in Table-5, which has demonstrated strong association of DFU with HTN, nephropathy and DKD/CKD (p-values < 0.0001 for all tested variables).

We also conducted statistical analysis in detail to find out cut-off points for HbA1c, serum creatinine and spot urine protein to detect the threshold levels of these variables which can significantly contribute to the development of DFU and can give indication to the physician that active intervention in required to prevent further complications. Hence, according to table-6, HbA1c values of $7.8 \%$ (g/dl) (with $60 \%$ sensitivity and $52 \%$ specificity), serum creatinine of $1.2 \mathrm{mg} / \mathrm{dl}$ (with $75 \%$ sensitivity and $48 \%$ specificity), and spot urine protein of $35 \mathrm{mg} / \mathrm{dl}$ (with $88 \%$ sensitivity and $90 \%$ specificity) was associated with development of DFU. Although microalbumin was studied in previous studies more extensively and was demonstrated to be a biomarker for CVD and incipient nephropathy. However, our current study for the first time has demonstrated that spot urine protein excretion from the kidney is also as strong risk factor and biomarker for the development of nephropathy and DFU. Glycemic control should be optimal and HbA1c should be near the targets (7 to 7.5\%) as current data has indicated that DFU was associated with elevated HbA1c (7.8\%). Better glycemic control improves wound healing and prevents diabetic complications.

Finally, it can be concluded that diabetic patients should be assessed and screened at early stages in tertiary care diabetes centres for the detection of HTN, nephropathy, neuropathy or diabetic foot screening, dyslipidaemia, and retinopathy as well to prevent complications and reduce health cost. Diabetes guidelines should be used to manage diabetes and its complications, including diabetic foot ulcers [25-30].

We have investigated for the first time risk factors such as elevated HbA1c, elevated BP or HTN, microalbuminuria, spot urine protein, for the development of DFU in the presence of nephropathy and DKD. We have also investigated association of low ABI with nephropathy and DKD. Our data analysis was in consistent with past studies. Further studies at multicentre level are required to confirm the results of the current study.

\section{Conclusion}

Our data has prompted and recommended diabetologists, endocrinologists, and physicians to use routine assessment and screening for diabetes complication detection. These include HTN, dyslipidaemia, nephropathy, DKD, routine assessment of the feet and peripheral circulation at regular intervals and to focus especially on increasing serum creatinine, proteinuria and renal failure (DKD/CKD) among the patients with diabetic foot ulcer or DFI. Patients with diabetes are at increased risk of foot ulcer development and progression. If the risk factors are already present, such as hypertension, cardiovascular disease, peripheral vascular disease and nephropathy or renal failure, then the risk is augmented with non-healing ulcer for a long time and poor prognosis with high morbidity and mortality [31-37]. Hence, according to our study it is recommended that physician should take detailed history, screening for risk factors, with complete laboratory analysis and management of risk factors simultaneously with best available medications to prevent further diabetes complications. Close follow up is required for those diabetic patients who have renal impairment with DSF as the research literature has shown poor prognosis for DSF with renal failure. Moreover, multidisciplinary approach is required including diabetologist, endocrinologist, nephrologist, diabetes educator, and chiropodist with foot and ankle surgeon to manage diabetes complications simultaneously.

\section{Declarations}

\subsection{Funding}

The authors received no financial support for the research, authorship, and/or publication of this article. 


\subsection{Ethical Approval}

All subjects gave their informed consent for inclusion before they participated in the study. The study was performed in accordance with the ethical standards as laid down in the 1975 Declaration of Helsinki (https://www.wma.net/what-we-do/medical-ethics/declaration-of-helsinki/), revised in 2013, and its later amendments or comparable ethical standards; and the protocol was approved by the Ethics Committee of Aseer Endocrine and Diabetes Center (No. 2005/08).

\subsection{Data Availability Statement}

The data presented in this study are available on request from the corresponding author. The data are not publicly available due to patient privacy and confidentiality reasons.

\subsection{Conflict of Interest}

The authors declare that they have no known competing financial interests or personal relationships that could have appeared to influence the work reported in this paper.

\section{References}

[1] King, H., Aubert, R. E., \& Herman, W. H. (1998). Global Burden of Diabetes, 1995-2025: Prevalence, numerical estimates, and projections. Diabetes Care, 21(9), 1414-1431. doi:10.2337/diacare.21.9.1414.

[2] Prompers, L., Huijberts, M., Apelqvist, J., Jude, E., Piaggesi, A., Bakker, K., ... Schaper, N. (2006). High prevalence of ischaemia, infection and serious comorbidity in patients with diabetic foot disease in Europe. Baseline results from the Eurodiale study. Diabetologia, 50(1), 18-25. doi:10.1007/s00125-006-0491-1.

[3] Lavery, L. A., Armstrong, D. G., Wunderlich, R. P., Tredwell, J., \& Boulton, A. J. M. (2003). Diabetic Foot Syndrome: Evaluating the prevalence and incidence of foot pathology in Mexican Americans and non-Hispanic whites from a diabetes disease management cohort. Diabetes Care, 26(5), 1435-1438. doi:10.2337/diacare.26.5.1435.

[4] Diabetes Control and Complications Trial Research Group. (1994). Effect of intensive diabetes treatment on the development and progression of long-term complications in adolescents with insulin-dependent diabetes mellitus: Diabetes Control and Complications Trial. Diabetes Control and Complications Trial Research Group. J pediatr, 125, 177-188.

[5] Kopple, J. D. (2001). National Kidney Foundation K/DOQI Clinical Practice Guidelines for Nutrition in Chronic Renal Failure. American Journal of Kidney Diseases, 37(1), S66-S70. doi:10.1053/ajkd.2001.20748.

[6] Sasso, F. C., De Nicola, L., Carbonara, O., Nasti, R., Minutolo, R., ... Salvatore, T. (2006). Cardiovascular Risk Factors and Disease Management in Type 2 Diabetic Patients With Diabetic Nephropathy. Diabetes Care, 29(3), $498-503$. doi:10.2337/diacare.29.03.06.dc05-1776.

[7] Papamichael, C. M., Lekakis, J. P., Stamatelopoulos, K. S., Papaioannou, T. G., Alevizaki, M. K., Cimponeriu, A. T., ... Stamatelopoulos, S. F. (2000). Ankle-brachial index as a predictor of the extent of coronary atherosclerosis and cardiovascular events in patients with coronary artery disease. The American Journal of Cardiology, 86(6), 615-618. doi:10.1016/s00029149(00)01038-9.

[8] Zheng, Z. J., Sharrett, A. R., Chambless, L. E., Rosamond, W. D., Nieto, F. J., Sheps, D. S., ... \& Heiss, G. (1997). Associations of ankle-brachial index with clinical coronary heart disease, stroke and preclinical carotid and popliteal atherosclerosis: the Atherosclerosis Risk in Communities (ARIC) Study. Atherosclerosis, 131(1), 115-125. doi:10.1016/s0021-9150(97)06089-9.

[9] Ix, J. H., Katz, R., De Boer, I. H., Kestenbaum, B. R., Allison, M. A., Siscovick, D. S., .. Criqui, M. H. (2009). Association of Chronic Kidney Disease with the Spectrum of Ankle Brachial Index. Journal of the American College of Cardiology, 54(13), 1176-1184. doi:10.1016/j.jacc.2009.06.017.

[10] Kitahara, T., Ono, K., Tsuchida, A., Kawai, H., Shinohara, M., Ishii, Y., ... Nojima, Y. (2005). Impact of Brachial-Ankle Pulse Wave Velocity and Ankle-Brachial Blood Pressure Index on Mortality in Hemodialysis Patients. American Journal of Kidney Diseases, 46(4), 688-696. doi:10.1053/j.ajkd.2005.06.016.

[11] Nosadini, R., Velussi, M., Brocco, E., Bruseghin, M., Abaterusso, C., Saller, A., ... Fioretto, P. (2000). Course of renal function in type 2 diabetic patients with abnormalities of albumin excretion rate. Diabetes, 49(3), $476-484$. doi:10.2337/diabetes.49.3.476.

[12] Tabaei, B. P., Al-Kassab, A. S., Ilag, L. L., Zawacki, C. M., \& Herman, W. H. (2001). Does Microalbuminuria Predict Diabetic Nephropathy? Diabetes Care, 24(9), 1560-1566. doi:10.2337/diacare.24.9.1560.

[13] Kramer, H. J., Nguyen, Q. D., Curhan, G., \& Hsu, C. Y. (2003). Renal Insufficiency in the Absence of Albuminuria and Retinopathy among Adults With Type 2 Diabetes Mellitus. JAMA, 289(24), 3273-3277. doi:10.1001/jama.289.24.3273. 
[14] MA Aziz, K. (2015). Correlation of urine biomarkers: microalbuminuria and spot urine protein among diabetic patients. Application of spot urine protein in diabetic kidney disease, nephropathy, proteinuria estimation, diagnosing and monitoring. Recent patents on endocrine, metabolic \& immune drug discovery, 9(2), 121-133.

[15] Rodby, R. A., Rohde, R. D., Sharon, Z., Pohl, M. A., Bain, R. P., \& Lewis, E. J. (1995). The urine protein to creatinine ratio as a predictor of 24-hour urine protein excretion in type 1 diabetic patients with nephropathy. American Journal of Kidney Diseases, 26(6), 904-909. doi:10.1016/0272-6386(95)90054-3.

[16] Côté, A.-M., Brown, M. A., Lam, E., Dadelszen, P. von, Firoz, T., Liston, R. M., \& Magee, L. A. (2008). Diagnostic accuracy of urinary spot protein:creatinine ratio for proteinuria in hypertensive pregnant women: systematic review. BMJ, 336(7651), 1003-1006. doi:10.1136/bmj.39532.543947.be.

[17] Morgenstern, B. Z., Butani, L., Wollan, P., Wilson, D. M., \& Larson, T. S. (2003). Validity of protein-osmolality versus protein-creatinine ratios in the estimation of quantitative proteinuria from random samples of urine in children. American Journal of Kidney Diseases, 41(4), 760-766. doi:10.1016/s0272-6386(03)00023-4.

[18] Margolis, D. J., Hofstad, O., \& Feldman, H. I. (2008). Association between Renal Failure and Foot Ulcer or Lower-Extremity Amputation in Patients with Diabetes. Diabetes Care, 31(7), 1331-1336. doi:10.2337/dc07-2244.

[19] Fernando, D. J. S., Hutchison, A., Veves, A., Gokal, R., \& Boulton, A. J. M. (1991). Risk Factors for Non-ischaemic Foot Ulceration in Diabetic Nephropathy. Diabetic Medicine, 8(3), 223-225. doi:10.1111/j.1464-5491.1991.tb01576.x.

[20] Guerrero-Romero, F., \& Rodríguez-Morán, M. (1998). Relationship of Microalbuminuria with the Diabetic Foot Ulcers in Type II Diabetes. Journal of Diabetes and Its Complications, 12(4), 193-196. doi:10.1016/s1056-8727(97)00112-8.

[21] Ndip, A., Rutter, M. K., Vileikyte, L., Vardhan, A., Asari, A., Jameel, M., ... Boulton, A. J. M. (2010). Dialysis Treatment Is an Independent Risk Factor for Foot Ulceration in Patients With Diabetes and Stage 4 or 5 Chronic Kidney Disease. Diabetes Care, 33(8), 1811-1816. doi:10.2337/dc10-0255.

[22] Morbach, S., Quante, C., Ochs, H. R., Gaschler, F., Pallast, J.-M., \& Knevels, U. (2001). Increased Risk of Lower-Extremity Amputation Among Caucasian Diabetic Patients on Dialysis. Diabetes Care, 24(9), 1689-1690. doi:10.2337/diacare.24.9.1689.

[23] Prompers, L., Schaper, N., Apelqvist, J., Edmonds, M., Jude, E., Mauricio, D., ... Huijberts, M. (2008). Prediction of outcome in individuals with diabetic foot ulcers: focus on the differences between individuals with and without peripheral arterial disease. The EURODIALE Study. Diabetologia, 51(5), 747-755. doi:10.1007/s00125-008-0940-0.

[24] National Institute of Diabetes, Digestive, Kidney Diseases (US). Division of Kidney, Urologic, Hematologic Diseases, Urban Institute. Renal Research Program, ... \& USRDS Coordinating Center. (2005). United States Renal Data System... Annual Data Report. National Institutes of Health, National Institute of Diabetes and Digestive and Kidney Diseases, Division of Kidney, Urologic, and Hematologic Diseases.

[25] Aziz, K. M. (2014). Bioenergetics: Open Access. Coronary artery disease (CAD), 12, 23.

[26] M. A. Aziz, K. (2016). Association of Hypothyroidism with Body Mass Index, Systolic Blood Pressure and Proteinuria in Diabetic Patients: Does treated Hypothyroidism with Thyroxine Replacement Therapy Prevent Nephropathy/Chronic Renal Disease? Current Diabetes Reviews, 12(3), 297-306. doi:10.2174/1573399812666151029101622.

[27] Muller, U. A., Femerling, M., Reinauer, K. M., \& Risse, A. (1999). Intensified treatment and education of type 1 diabetes as clinical routine. Diabetes Care, 22, B29.

[28] Ahmed Aziz, K. M. (2018). Association of Diabetic Retinopathy and Maculopathy with Elevated HbA1c, Blood Pressure, Serum Creatinine, Microalbuminuria, Spot Urine Protein, Nephropathy and Diabetic Kidney Disease. An Experience from Data Analysis of 10,580 Diabetic Patients. Journal of Endocrinology and Diabetes, 5(1), 1-11. doi:10.15226/23746890/5/1/00195.

[29] Bakker, K., Apelqvist, J., Lipsky, B. A., Van Netten, J. J., \& Schaper, N. C. (2016). The 2015 IWGDF guidance documents on prevention and management of foot problems in diabetes: development of an evidence-based global consensus. Diabetes/Metabolism Research and Reviews, 32, 2-6. doi:10.1002/dmrr.2694.

[30] Aziz, K. M. (2013). The Diabetic Foot Syndrome an Ignored and Potential Problem in Medical Practice. Int J Diabetol Vasc Dis Res, 1(1), 1-3.

[31] Boyko, E. J., Seelig, A. D., \& Ahroni, J. H. (2018). Limb- and Person-Level Risk Factors for Lower-Limb Amputation in the Prospective Seattle Diabetic Foot Study. Diabetes Care, 41(4), 891-898. doi:10.2337/dc17-2210.

[32] Iwase, M., Fujii, H., Nakamura, U., Ohkuma, T., Ide, H., Jodai-Kitamura, T., ... Kitazono, T. (2018). Incidence of diabetic foot ulcer in Japanese patients with type 2 diabetes mellitus: The Fukuoka diabetes registry. Diabetes Research and Clinical Practice, 137, 183-189. doi:10.1016/j.diabres.2018.01.020. 
[33] Adem, A. M., Andargie, A. A., Teshale, A. B., \& Wolde, H. F. (2020). Incidence of Diabetic Foot Ulcer and Its Predictors Among Diabetes Mellitus Patients at Felege Hiwot Referral Hospital, Bahir Dar, Northwest Ethiopia: A Retrospective FollowUp Study. Diabetes, Metabolic Syndrome and Obesity: Targets and Therapy, Volume 13, 3703-3711. doi:10.2147/dmso.s280152.

[34] Yazdanpanah, L., Shahbazian, H., Nazari, I., Hesam, S., Ahmadi, F., Cheraghian, B., ... Mohammadianinejad, S. E. (2018). Risk factors associated with diabetic foot ulcer-free survival in patients with diabetes. Diabetes \& Metabolic Syndrome: Clinical Research \& Reviews, 12(6), 1039-1043. doi:10.1016/j.dsx.2018.06.020.

[35] Monteiro - Soares, M., Russell, D., Boyko, E. J., Jeffcoate, W., Mills, J. L., ... Morbach, S. (2020). Guidelines on the classification of diabetic foot ulcers (IWGDF 2019). Diabetes/Metabolism Research and Reviews, 36(S1). doi:10.1002/dmrr.3273.

[36] Mader, J. K., Haas, W., Aberer, F., Boulgaropoulos, B., Baumann, P., Pandis, M., ... Sourij, H. (2019). Patients with healed diabetic foot ulcer represent a cohort at highest risk for future fatal events. Scientific Reports, 9(1). doi:10.1038/s41598-01946961-8.

[37] Jeyaraman, K., Berhane, T., Hamilton, M., Chandra, A. P., \& Falhammar, H. (2019). Mortality in patients with diabetic foot ulcer: a retrospective study of 513 cases from a single Centre in the Northern Territory of Australia. BMC Endocrine Disorders, 19(1). doi:10.1186/s12902-018-0327-2. 